\title{
Implementasi Pembelajaran Worksheet Berbasis ICT Untuk Peningkatan Kemampuan High Order Mathematical Thinking (HOMT) Siswa SMP
}

\author{
Ratni Purwasih ${ }^{1 *}$, Usman Aripin ${ }^{2}$, Aflich Yusnita Fitrianna ${ }^{3}$ \\ 1, 2, ${ }^{3}$ Program Studi Pendidikan Matematika, IKIP Siliwangi Bandung \\ *E-mail : ratnipurwasih61@gmail.com
}

Article received :06-08-2018, article revised :03-09-2018, article published: $d d$ mm yy

DOI : 10.25273/jipm.v7i1.3064

\begin{abstract}
Abstrak
Penelitian ini dilatarbelakangi oleh rendahnya tingkat belajar siswa dipengaruhi oleh persepsi mengenai pembelajaran matematika yang dianggap sulit. Siswa harus mengembangkan pengetahuan baru mereka secara aktif dari pengalaman dan pengetahuan sebelumnya sehingga dibutuhkan kemampuan High Order Mathematical Thinking (HOMT) siswa SMP. Untuk mengatasi permasalahan tersebut diperlukan salahsatu model pembelajaran yang diharapkan mampu mengembangkan kemampuan High Order Mathematical Thinking (HOMT) siswa adalah pembelajaran worksheet berbasis ICT. Melalui pembelajaran ini terdapat lembaran-lembaran berisi tugas instruksional yang terdiri dari serangkaian pertanyaan dan informasi yang dirancang berbasis ICT untuk membimbing siswa agar memahami masalah matematika yang memuat soal-soal sistematis bertujuan meningkatkan High Order Mathematical Thinking (HOMT) siswa. Metode penelitian yang digunakan adalah quasi experimental dengan bentuk desain Nonequivalent Control Group Design, dimana subyek penelitian tidak dikelompokkan secara acak. Data dalam penelitian ini dikumpulkan melalui pretes dan postes kemampuan HOTM siswa.Tujuan dalam penelitian ini adalah mengkaji pencapaian dan peningkatan kemampuan high order mathematical thinking (HOMT) siswa SMP di kelas yang mendapat pembelajaran Worksheetberbasis ICT lebih baik daripada siswa di kelas yang mendapatkan pembelajaran ekspositori.Hasil dari peenlitian ini adalah peningkatan kemampuan HOTM siswa SMP yang menggunakan pembelajaran worksheet berbasis ICT lebih baik dibandingkan kelas yang pembelajarannnya menggunakan ekspositori.
\end{abstract}

Kata Kunci: Kemampuan High Order Mathematical Thinking (HOMT), Pembelajaran worksheet berbasis ICT

\section{PENDAHULUAN}

Keberhasilan pembelajaran di pengaruhi oleh faktor internal dan eksternal. Pembelajaran tidak akan berhasil tanpa adanya aktivitas yang sinergis antara guru, siswa dan metode pembelajaran yang digunakan. Pembelajaran merupakan proses perubahan kognitif, afektif maupun psikomotorik. Hal ini sejalan dengan Sumbogo (2016, p. 180) mengatakan bahwa faktor-faktor yang mempengaruhi jalannya proses pembelajaran matematika di sekolah diantaranya adalah faktor guru, siswa, metode pembelajaran, buku pelajaran, alat pembelajaran, lingkungan keluarga, lingkungan sekolah maupun pemerintah. Pembelajaran yang berhasil mampu mengkonstruksi kemampuan kognitif siswa untuk menambah pengetahuan. Hal ini sependapat dengan Joyce, Weil \& Calhoun (Rahmawati \& Suryanto, p. 89) 
yaitu "...the idea that learning is the construction of knowledge". Dengan demikian, proses pembelajaran matematika memberikan kesempatan siswa untuk belajar menggali pengetahuannya sendiri.

Soedjadi (Aripin \& Purwasih, 2017) menyatakan bahwa salah satu fungsi matematika sekolah adalah sebagai sarana penataan nalar peserta didik. Dengan mempelajari metematika, siswa diharapkan dapat bernalar dan berpikir secara logis, analitis, kritis, dan kreatif.Inilah yang menjadikan matematika menjadi salah satu mata pelajaran yang penting untuk dipelajari di berbagai jenjang karena itu menurut Russeffendi (2010) matematika merupakan ratunya ilmu yang artinya matematika pelayan bagi beberapa disiplin ilmu lainnya.

Pembelajaran matematika dianggap sulit oleh sebagian siswa merupakan salah satu faktor rendahnya prestasi belajar.Hal ini sejalan dengan Rizki \& Wildaniati $(2015$, p. 1) mengatakan bahwa pembelajaran matematika dianggap sebagian peserta didik merupakan pelajaran yang sulit. Hal ini dikarenakan siswa masih memiliki rasa males untuk mempelajari materi matematika secara teratur. Berbagai cara pendekatan sudah banyak digunakan oleh guru untuk memberikan solusi pada proses pembelajaran. Untuk mengatasi masalah tersebut, mulai dari mengubah metode pembelajaran ceramah menjadi pembelajaran inovatif maupun mengembangkan perangkat pembelajarannya. Dari konsep materi yang disampaikan, siswa masih bingung antara teori dasar yang ada dengan contoh aplikasi dalam kehidupan sehari-hari.

Sumarmo (2013, p. 64) emphasized that Higher Order Thinking (abbreviated as HOT) means a capacity beyond the information given, with action to evaluate critically, combined whith metacognitive awereness, and has an ability of solving problems. NCTM (Yaniawati, 2013, P. 110) menyatakan bahwa peserta didik harus belajar matematika dengan pengertian, artinya peserta didik harus mengembangkan pengetahuan baru mereka secara aktif dari pengetahuan awal sebelumnya. Untuk mencapai hal tersebut, dirumuskan dalam 5 tujuan umum pembelajaran matematika, yaitu: (1) belajar berkomunikasi (komunikasi matematis); (2) belajar soal (penalaran matematis); (3) belajar memecahkan masalah (pemecahan masalah matematis); (4) belajar menghubungkan ide (koneksi matematis); (5) membentuk sikap positif terhadap matematika (sikap positif terhadap matematika). Keterampilan ini biasanya disebut High Order Thinking Skills (HOTS). Di era global ini, untuk mengembangkan keterampilan ini dibutuhkan akselerasi dalam proses pembelajaran matematika, karena inovasi informasi sering terjadi sangat cepat.

Salah satu pembelajaran yang berpeluang untuk mengembangkan kemampuan HOMT siswa adalah pembelajaran dengan worksheet berbasis ICT. ICT atau Information and Communication Technology merupakan sarana untuk peningkatan keilmuan untuk penerapan pembelajaran. Melalui ICT diharapkan lebih memberikan kemanfaatan dalam proses kegiatan belajar dan mengajar yang menyebabkan siswa menjadi lebih termotivasi. Hal ini sejalan dengan Rizki \& Wildaniati (2015, p.2) mengungkapkan bahwa kemajuan perkembangan ICT membuat semua orang harus bergerak menyesuaikan dan memanfaatkannya dengan baik. Pesatnya Information and Communication Technology (ICT) harus dapat menstimulus dan 
memanfaatkannya secara baik. ICT memiliki peranan baik apabila dikelola dan dijadikan salah satu alat untuk pendamping proses pembelajaran.

Lembar kerja siswa (worksheet) merupakan salah satu bahan ajar yang dipergunakan oleh pengajar untuk mengarahkan proses pembelajaran. Berbagai jenis dan bentuk worksheet berisikan latihan-latihan soal yang rutin menyebabkan siswa merasa bosan dan jenuh mengisi worksheet tersebut. Sejalan dengan Suyitno (Fannie \& Rohati, 2014, 98) bahwa lembar kerja atau worksheet biasanya lembar kerja yang berisikan informasi tentang ide materi yang dipelajari melalui kegiatan yang sistematis. Beberapa worksheet mata pelajaran yang boleh kategorikan kurang diminati siswa seperti IPA, Matematika dan Bahasa Inggris. Apabila tampilan dan isi dari worksheet tidak dibarengi dengan pembelajaran inovatif maka siswa akan cepat jenuh dan malas untuk mengerjakan worksheet tersebut. Permasalahan ini yang menjadi dasar melakukan penelitian untuk mengetahui penerapan pembelajaran worksheet berbasis ICT (Information and Communication Technology) yang akan dikembangkan. Dengan harapan bahwa pembelajaran worksheet berbasis ICT ini dapat membantu mengembangkan kemampuan High Order Mathematical Thinking yang selanjutnya di singkat HOMT. Pada saat pembelajaran worksheet, disajikan soal-soal yang memiliki indikator kemampuan HOMT. Melalui worksheet berbasis ICT ini kemampuan HOMT siswa dilatih agar meningkat dan berkembang. Adapun judul penelitian ini adalah implementasi pembelajaran worksheet berbasis ICT terhadap pening- katan kemampuan high order mathematical thinking siswa SMP.

Proses menganalisis, mengevaluasi, dan menerapkan konsep matematika dalam memberikan solusi terhadap persoalan dengan strategi yang tepat. Berbagai keterampilan tersebut oleh Brookhart (Musfiqi \& Jailani, 2014, p.47) disebut sebagai high order thinking skill (HOTS) atau keterampilan berpikir tingkat tinggi. Menurut Liu dan Fisher (Musfiqi\& Jailani, 2014, p. 47) mengungkapkan bahwa klasifikasi HOTS terdiri dari proses kognitif analisis, sintesis dan evaluasi sedangkan pengetahuan, pemahaman dan penerapan sebagai lower order thinking skill (LOTS). Selanjutnya Sumarmo (2013) mengungkapkan bahwa HOMT adalah bagian dari ranah kognitif taksonomi Bloom yang meliputi analisis, sintesis dan evaluasi. Meskipun definisi HOTS masih banyak diperdebatkan, secara umum HOTS dapat diartikan sebagai pola pikir individu yang melibatkan pengolahan informasi secara kritis dan kreatif dalam menghadapi situasi atau menyelesaikan permasalahan tertentu.

Lembar kerja atau worksheet merupakan kumpulan materi pelajaran dan soal-soal latihan untuk membimbing siswa lebih sistematis dan terarah proses belajarnya. Menurut Choo, Serene S. Y. et al (Indriyati, 2015, p.31) worksheet adalah alat instruksional yang terdiri dari serangkaian pertanyaan dan informasi yang didesain sebagai petunjuk siswa agar memahami ide-ide yang kompleks karena mereka bekerja melalui secara sistematis.

\section{METODE}


Penelitian yang digunakan adalah penelitian quasi experimental dengan bentuk desain nonequivalent control group design, dimana subyek penelitian tidak dikelompokkan secara acak. Adapun desain penelitian menurut Russeffendi (2010) yang digunakan pada penelitian ini adalah sebagai berikut :
A $\mathrm{O} \quad \mathrm{X} O$
Kelas eksperimen
A $\mathrm{O} \quad \mathrm{O}$
Kelas kontrol

Keterangan:

$\mathrm{A}=$ acak kelas

$\mathrm{O}=$ pretes $=$ postes (tes kemampuan High Order

Mathematical Thinking )

$\mathrm{X}=$ Pembelajaran worksheet berbasis ICT
Data dalam penelitian ini dikumpulkan melalui tes kemampuan HOTM matematis. Data kemampuan berpikir kreatif matematis siswa dikumpulkan melalui pretes dan postes. Penelitian ini diolah dengan menggunakan SPSS dengan langkah-langkah yaitu melakukan uji normalitas, melakukan uji homogenitas varians, uji Signifikan perbedaan Rata-rata, uji Gain Ternormalisasi. Untuk mengetahui seberapa besar peningkatan kemampuan HOTM matematik siswa sebelum dan sesudah kegiatan pembelajaran, dilakukan perhitungan gain ternormalisasi dari Hake (Aripin \& Purwasih, 2017), sebagai berikut:

$$
\text { Gain Ternomalisasi }(g)=\frac{\text { Skor tes akhir }- \text { skor tes awal }}{\text { skor maksimum ideal }- \text { skor tes awal }}
$$

\section{HASIL DAN PEMBAHASAN}

Setelah melakukan pembelajaran berbasis worksheet berbasis ICT pada kelas eksperimen dan pendekatan konvensional pada kelas kontrol, selanjutnya dilakukan analisis data skor penelitian tes kemampuan HOTM . Hasil tes kemampuan HOTM siswa SMP terlihat pada Tabel 1 di bawah ini.

Tabel 1. Statistik Deskriptif Hasil TesKemampuan Berpikir Kreatif

\begin{tabular}{cccccccc}
\hline Kemampuan & \multicolumn{4}{c}{ Kelas Eksperimen } & \multicolumn{3}{c}{ Kelas Kontrol } \\
\cline { 2 - 7 } & & Pretes & Postes & Gain & Pretes & Postes & Gain \\
\hline High Order & $\bar{x}$ & 1,06 & 8,24 & 0,26 & 1,08 & 6,912 & 0,29 \\
Thinking & $\mathrm{S}$ & 1,09 & 8,24 & 0,16 & 1,28 & 3,07 & 0,19 \\
Mathematic & & & & & & & \\
(HOTM) & & & & & & \\
\hline
\end{tabular}

Tabel 1 di atas terlihat jelas bahwa gain kelas kontrol dan kelas eksperimen ada selisihnya yaitu sebesar 0,10 ini menunjukan bahwa terdapat perbedaan yang signifikan antara kelas eksperimen dan kelas kontrol. Data postes kemampuan HOTM digunakan uji t. Uji t' dilakukan dengan menggunakan bantuan software SPSS 21. Hipotesisnya dirumuskan sebagai berikut ini:
$\mathbf{H}_{\mathbf{0}}: \mu_{1} \leq \mu_{2}:$ Implementasi pembelajaran Wokhseet berbasis ICT untuk peningkatan kemampuan HOTM siswa SMP tidak lebih baik atau sama dengan siswa yang pembelajarannya menggunakan pendekatan konvensional.

$\mathbf{H}_{\mathbf{A}}: \mu_{1}>\mu_{2}$ : Implementasi pembelajaran Wokhseet berbasis ICT untuk peningkatan kemampuan HOTM siswa SMPlebih baik daripada siswa yang pembelajarannya menggunakan pendekatan konvensional 
JIPM (Jurnal Ilmiah Pendidikan Matematika), 7(1), September 2018- 61

Usman Aripin, Aflich Yusnita Fitrianna, Ratni Purwasih

Kriteria pengujian :

JikaSig $<0,05$ maka $\mathrm{H}_{0}$ ditolak

Jika $\mathrm{Sig} \geq 0,05$ maka $\mathrm{H}_{0}$ diterima

Tabel 2. Hasil Uji t Data Gain

\begin{tabular}{|c|c|c|c|c|c|c|}
\hline \multirow{3}{*}{ Gain } & \multirow{3}{*}{$\mathrm{T}$} & \multicolumn{3}{|c|}{ t-test for Equality of Means } & \multirow{2}{*}{\multicolumn{2}{|c|}{$\begin{array}{l}95 \% \text { Confidence } \\
\text { Interval of the Difference }\end{array}$}} \\
\hline & & Df & $\begin{array}{l}\text { Sig. (2- } \\
\text { tailed) }\end{array}$ & $\begin{array}{c}\text { Mean } \\
\text { Difference }\end{array}$ & & \\
\hline & & & & & Lower & Upper \\
\hline $\begin{array}{l}\text { Equal variances } \\
\text { assumed }\end{array}$ & 2.569 & 72 & 0.012 & 0.08733 & 0.01822 & 0.16745 \\
\hline $\begin{array}{l}\text { Equal variances not } \\
\text { assumed }\end{array}$ & 2.569 & 69.8 & 0.012 & 0.08733 & 0.01822 & 0.16745 \\
\hline
\end{tabular}

Terlihat pada Tabel 2 didapat Sig sebesar 0,012. Menurut Uyanto (2009: 145) karena kita akan menguji 1 arah (1tailed) maka signifikasi untuk 2-tailed harus di bagi dua. Nilai signifikansinya adalah $\frac{0,013}{2}=0,0060$. Karena sig $<0,05$ dengan kata lain $\mathrm{H}_{0}$ ditolak artinya implementtasi pembelajaran Wokhseet berbasis ICT untuk peningkatan kemampuan HOTM siswa SMP lebih baik daripada siswa yang menggunakan pendekatan konvensional pada taraf signifikansi 5\%.

Penelitian ini bertujuan untuk mengkaji pencapain dan peningkatan kemampuan high order mathematical thinking siswa di kelas yang mendapat pembelajaran Worksheet berbasis ICT lebih baik daripada siswa di kelas yang mendapatkan pembelajaran ekspositori.

Mengacu pada pernyataan tersebut, kegiatan pembelajaran yang di berikan pada kelas kontrol dengan pembelajaran ekspositori dan pada kelas eksperimen dengan pembelajaran worksheet berbasis ICT sangat berbeda sekali, baik itu pada tingkat keaktifan siswa, cara belajar siswa atau pun antusias semangat siswa terhadap pelajaran matematika, hal tersebut terlihat pada gambar 1 berikut:

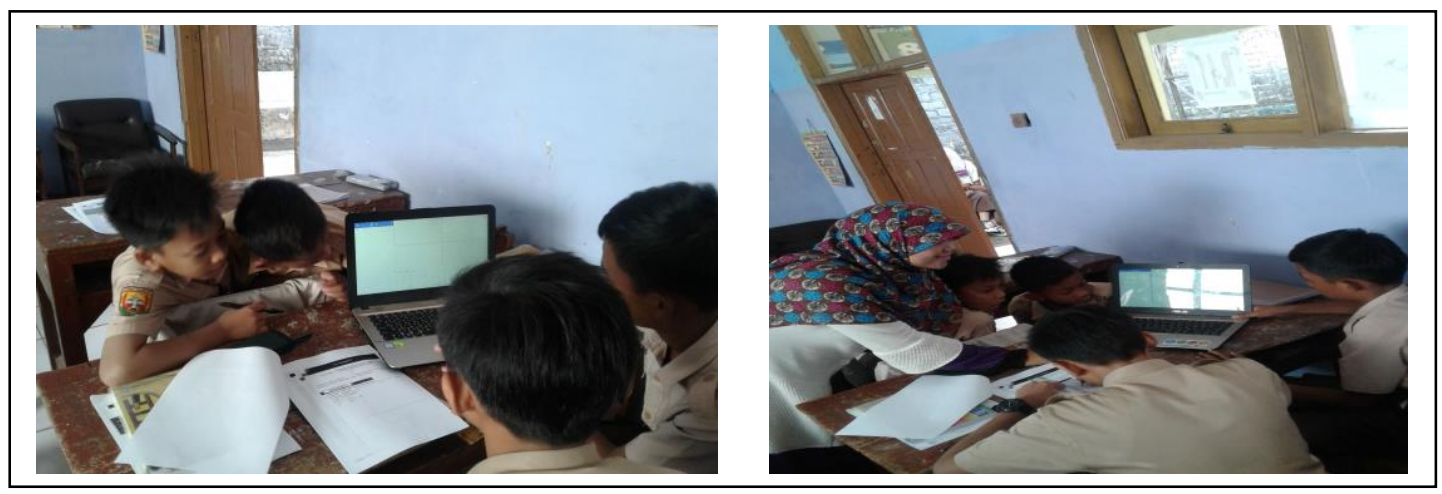

Gambar. 1 Aktifitas Siswa yang Memperoleh Pembelajaarn Worksheet Berbasis ICT

Pada Gambar 1 karakteristik pembelajaran worksheet berbasis ICT membuat suasana kelas aktif siswa selalu mengerjakan prosedur dan langkah pengerjaan worksheet sesuai software Geogebra yang ada di layar monitor, adanya proses diskusi sehingga siswa yang belum paham mengenai apa yang sedang dipelajari 
terstimulus untuk bertanya dan bahkan cendrung berusaha pahaman materi diskusi. Hasil analisis penelitian menunjukan bahwa pencapaian peningkatan kemampuan HOTM siswa SMP yang memperoleh pembelajaran worksheet berbasis ICT lebih baik daripada yang memperoleh pembelajaran biasa. Berdasarkan pengamatan penulis di lapangan kemampuan berpikir kreatif matematik siswa kelas yang menggunakan pembelajaran waorksheet berbasis ICT lebih baik dikarenakan siswa terbiasa mencari tahu sendiri juga menyelesaikan masalah hasil pemikiran sendiri melalui software Geogebra pada layar monitor. Sejalan dengan Umbara (Aripin \& Purwasih, 2017) bahwa selama pengumpulan informasi terjadi kegiatan berpikir yang kemudian akan menimbulkan pemahaman yang mendalam dalam belajar dan akan mendorong terjadinya pemusatan perhatian terhadap topik sehingga membuat siswa menggali lebih banyak informasi yang membuat hasil belajar lebih bermutu. Hal ini sejalan dengan hasil penelitian dari Rizki \& Wildaniati (2015) bahwa ada pengaruh yang sangat signifikan penggunaan bahan ajar berbasis ICT terhadap hasil belajar. Dengan kata lain, bahan ajar berbasis ICT tersebut sangat efektif untuk digunakan dalam proses pembelajaran.

Berbeda dengan kelas yang menggunakan pembelajaran biasa karena pada kelas kontrol siswa terbiasa menerima penjelasan dari guru sehingga siswa besar kemungkinan mengalami kesulitan jika tidak mendapat bantuan dari guru.Untuk keaktifan berdiskusi kelompok siswa kelas eksperimen sebagian besar kelompok berdiskusi dengan aktif, sedangkan pada kelas kontrol hanya sebagian kecil kelompok yang berdiskusi dengan aktif dan interaktif. Pada Gambar 2 karakteristik pembelajaran konvensional membuat suasana kelas cendrung bosen, siswa selalu mengerjakan prosedur dan langkah pengerjaan sesuai contoh-contoh yang diberikan oleh guru, dan tidak adanya proses diskusi sehingga siswa yang belum paham mengenai apa yang sedang dipelajari takut bertanya dan bahkan cendrung membiarkan ketidak pahamannya dikarnakan tidak adanya kesempatan untuk bertanya maupun berdiskusi. Sejalan dengan Hiebert, dkk. (Aripin \& Purwasih, 2017). Bukti menunjukan jika siswa belajar dengan mengingat dan latihan prosedural, mereka akan kesulitan dalam memperoleh tes konsep konsep mematika secara mendalam. Hal tersebut terlihat pada Gambar 2 berikut ini.

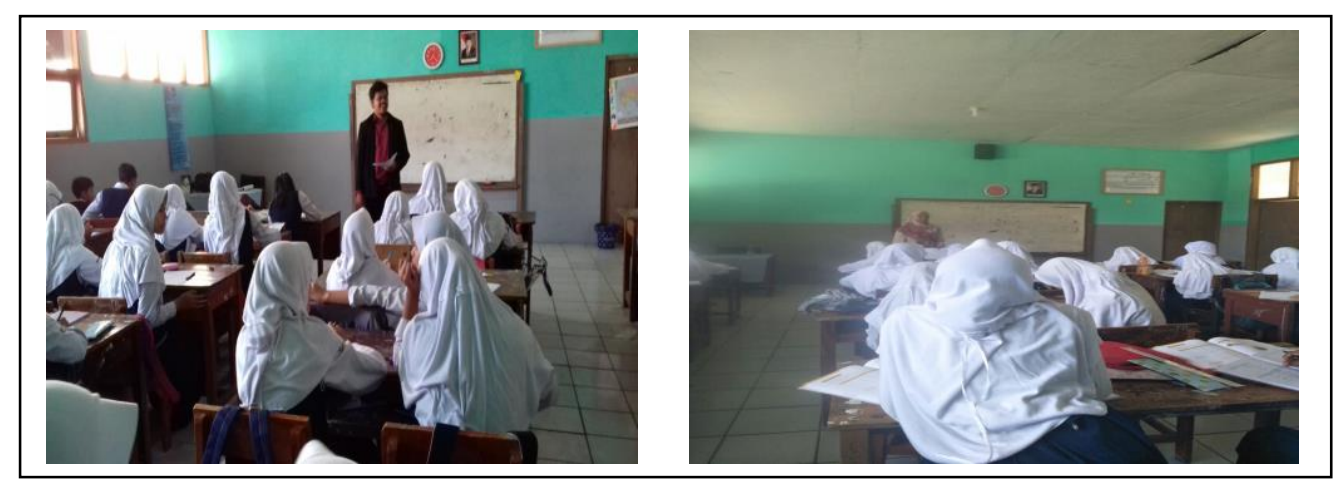

Gambar 2. Suasana Belajar Kelas yang Menggunakan Pembelajaran Ekspositori 
Suasana kelas yang pembelajarannya menggunakan pendekatan ekspositori tampak pasif dan sumber belajar terpusat kepada guru. Siswa hanya menerima materi dari guru dan cenderung kurang aktif pada saat proses pembelajaran berlangsung. Kelas yang mengguakan pembelajaran biasa, sebagian besar siswa masih kesulitan menyelesaikan soal berindikator HOTM. Siswa di kelas kontrol terbiasa menyelesaikan soal sesuai dengan cara yang telah guru ajarkan. Ikhsanudin (2014) mengatakan bahwa mereka cenderung senang dengan cara yang singkat dibandingkan dengan cara yang panjang seperti langkah penyelesaian masalah yang disediakan pada lembar jawaban. Proses menganalisis, mengevaluasi, dan menerapkan konsep matematika dalam memberikan solusi terhadap persoalan dengan strategi yang tepat. Berbagai keterampilan tersebut oleh Brookhart (Musfiqi \& Jailani, 2014, p.47) disebut sebagai high order thinking skill (HOTS) atau keterampilan berpikir tingkat tinggi. Menurut Liu dan Fisher (Musfiqi\& Jailani, 2014, p. 47) mengungkapkan bahwa klasifikasi HOTS terdiri dari proses kognitif analisis, sintesis dan evaluasi sedangkan pengetahuan, pemahaman dan penerapan sebagai Lower Order Thinking Skill (LOTS). Indikator tersebut muncul pada beberapa siswa di kelas eksperimen, mereka terstimulus kemampuan analisisnya melalui pembelajaran worksheet berbasis ICT dan cenderung berpikir kreatif saat diskusi berlangsung. Dimana lembar kegiatan siswa berisi kegiatan penemuan dari materi persamaan garis melalui software Geogebra. Siswa mengerjakan lembar kegiatan siswa yang membahas soal-soal HOT yang ada di LKS melalui software
Geogebra. Hasil yang diperoleh melalui software Geogebra dan hasil dari pengerjaan sendiri lalu dibandingkan serta di analisis proses penyelesaiannya. Siswa pada fase ini dilatih untuk berpikir kreatif menganalisa dan mengemukakan pendapatnya pada saat proses diskusi berlangsung.

Berdasarkan pengamatan salama penelitian di peroleh beberapa catatan penting yaitu, (1) kemampuan siswa dalam mengaitkan informasi pada soal yang diberikan masih perlu ditingkatkan, salah satu penyebab masalah tersebut adalah siswa merasa bingung saat konsep diaplikasikan pada software Geogebra, (2) kesalahan yang terjadi pada umumnya adalah karena siswa kurang cermat dalam menemukan hasil dari output Geogebra, (3) kemampuan siswa dalam menyelesaikan masalah meningkat pesat pada siswa di kelas eksperimen menggunakan worksheet berbasis ICT yang dikembangkan, hal ini dikarenakan siswa telah terlatih dalam menyelesaikan berbagai masalah yang disajikan dalam LKS. Dalam pembelajaran, siswa dibiasakan untuk mencocokan gagasanhasil manual dengan hasil software Geogebra untuk menyelesaikan masalah sehingga siswa dapat mengetahui kesalahannya. Kemampuan siswa di kelas eksperimen bertambah pengetahuan berkenaan dengan konsep matematika menggunakan software Geogebra dan siswa merasa senang karena Geogebra bias langsung terlihat output dari soal yang ada di LKS.Selain itu, kecenderungan siswa yang belajar dengan berbantuan ICT lebih termotivasi untuk mencoba menyelesaikan soal LKS dan teman anggota kelompok terpengaruh dari motivasi yang ditularkan oleh anggota kelompoknya. Motivasi itu bisa muncul 
dari diri sendiri maupun dari luar (ekstrinsik). Sebagaimana penelitian dari Pramesti (Puspitasari, Nurjaman, \& Purwasih, 2017) bahwa terdapat korespondensi yang baik antara prestasi seseorang terhadap teman sekitarnya.

\section{SIMPULAN}

\section{DAFTAR PUSTAKA}

Fannie1, R.D. \& Rohati. 92014). Pengembangan Lembar Kerja Siswa (Lks) Berbasis Poe (Predict, Observe, Explain) Pada Materi Program Linear Kelas Xii Sma. Jurnal Sainmatika, 8(1), 96-106.

Indriyati.( 2015 ). Penerapan metode worksheet plus pada proses pembelajaran materi menjaga kelangsungan hidup. Didaktikum: Jurnal Penelitian Tindakan Kelas, 16(3), 31-36.

Mukhid, Abd. (2009). Self- Efficacy (Perspektif Teori Kognitif Sosial dan Implikasinya terhadap Pendidikan. Jurnal Tadris , 4 (1), 106122.

Musfiqi, S., \& Jailani. (2014). Pengembangan Bahan Ajar Matematika yang Berorientasi pada Karakter dan High Order Thinking Skill (HOTS). Pythagoras, Jurnal Pendidikan Matematika, 9(1),(4559).

Puspitawedana, D., \& Jailani.(2016). The Use of Problem Based Learning to Improve Higher Order Thinking Skills in Junior Secondary School. Proceeding Of 3Rd International Conference on Research, Implementation and education of Mathematics and Science. UNY: Yogjakarta.
Berdasarkan hasil penelitian, ada beberapa hal simpulan yang diperoleh yaitu, (1) peningkatan kemampuan HOTM siswa SMP yang pembelajarannya menggunakan worksheet berbasis ICT lebih baik dibandingkan kelas ekspositori, (2) siswa cenderung aktif di kelas yang pembelajarannya menggunakan ICT.

Puspitasari, I., Nurjaman, A., \& Purwasih, P. (2017). Analisis Hambatan Belajar Mahasiswa Pada Mata Kuliah Program Linear. JIPM (Jurnal Ilmiah Pendidikan Matematika) 6(1), 39-46.

Rahmawati, U \& Suryanto, (2014). Pengembangan Model Pembelajaran Matematika Berbasis Masalah Untuk Siswa SMP. Jurnal Riset Pendidikan Matematika, 1(1), 8897.

Rizki1, S \& Wildaniati, Y. (2015). Efektifitas Bahan Ajar dan Media Berbasis ICT Pada Materi Persamaan dan Fungsi Kuadrat. Jurnal Pendidikan Matematika FKIP Univ. Muhammadiyah Metro, 4(2), 1-8.

Ruseffendi, E.T (2010). Dasar-dasar Penelitian Pendidikan dan Bidang Non-Eksakta Lainnya. Bandung: Tarsito.

Sumarmo, U. (2013). Kumpulan Makalah Berpikir dan Disposisi Matematik serta Pembelajarannya. Jurusan Pendidikan Matematika FPMIPA UPI: Bandung.

Sumarmo, U. (2014). Mengembangkan Instrumen Untuk Mengukur Higher Order Thinking Matematichal Thinking Skills. Makalah disajikan dalam Workshop Pendidikan 
JIPM (Jurnal Ilmiah Pendidikan Matematika), 7(1), September 2018- 65

Usman Aripin, Aflich Yusnita Fitrianna, Ratni Purwasih

Matematika di Universitas Islam Jakarta. 22 oktober 2014.

Saputra, P.R. (2016). Pembelajaran Geometri Berbantuan Geogebra dan Cabri Ditinjau dari Prestasi Belajar, Berpikir Kreatif dan SelfEfficacy.PYTHAGORAS, Jurnal Pendidikan Matematika, 11(1), 5968. doi: http://dx.doi.org/10.21831/ pg.v11i1.9680.

Sariningsih, R \& Purwasih, R. (2017). Pembelajaran Problem Based Learning untuk Meningkatkan Kemampuan Pemecahan Masalah Matematis dan Self Efficacy Mahasiswa Calon Guru.Jurnal Nasional Pendidikan Matematika, 1(1), 163-177.

Sujoko. (2013). Pemanfaatan Teknologi Informasi dan Komunikasi sebagai Media Pembelajaran di SMP Negeri 1 Geger Madiun. Jurnal Kebijakan dan Pengembangan Pendidikan, 1(1), 71-77.

Sumbogo, B.M. (2016). Upaya Meningkatkan Aktivitas dan Hasil Belajar
Matematika Menggunakan Media CD Pembelajaran Disertai Pemberian Tugas Pada Siswa Kelas Vii Smp Negeri 1 Banjar Margo. Aksioma Jurnal Pendidikan Matematika FKIP Univ. Muhammadiyah Metro , 5(2), 180-186.

Aripin, U., \& Purwasih, R. (2017). Penerapan Pembelajaran Berbasis Alternative Solutions Worksheet Untuk Meningkatkan Kemampuan Berpikir Kreatif. Aksioma: Jurnal Program Studi Pendidikan Matematika, 6(2), 225-233.

Yaniawati, R.P. (2013). E-Learning to Improve Higher Order Thinking Skills (HOTS) of Students.Journal of Education and Learning. 7 (2), 109-120.

Yoenanto, N. H. (2010). Hubungan antara Self-Regulated Learning dengan Self-Efficacy pada Siswa Akselerasi Sekolah Menengah Pertama di Jawa INSAN 12 (2), 8894 